\title{
MODIFICATION OF AN ADULT VENTILATOR TO AN INFANT VENTILATOR?
}

\author{
John G. JAeger, M.D., Robert M. SMITH, M.D. ${ }^{3}$ \\ and Dean Crocker, M.D.*
}

\section{INTRODUCTION}

Bendixen ET aL. ${ }^{1}$ AND SAFAR ET aL. ${ }^{2}$ have stated criteria which an acceptable ventilator should meet and these include:

1. mechanical dependability

2. basic controls clearly delineated and properly marked

3. $\mathrm{FiO}_{2}$ available over a range of 20 per cent to 100 per cent

4. adequate humidification with a controllable degree of humidity

5. sensitive patient-triggering device with a reliable automatic cycling device

6. ability to monitor tidal volume and airway pressure

7. independent variation of inspiratory and expiratory phases over a wide range

8. one-way valving in a volume-limited ventilator open to atmosphere so that a patient may inspire during any phase of respiration

9. alarm systems to warn of electrical, oxygen supply, or mechanical failure

10. easy disinfection

11. ability to reproduce the normal parameters of respiration: gas flow rate, volume, and frequency

To these we would add:

12. a backup system

13. ability to ventilate all types of patients, i.e., adults and infants

Problems arising during mechanical ventilation of infants include: small tidal volumes; rapid respiratory frequency; low inspiratory flows; low compliance; compressibility of gas within a large mechanical deadspace ${ }^{3}$ and the use of heavy, bulky apparatus near the patient's face, which may cause accidental extubation and interferes with nursing care.

Most ventilators designed for adults have not been able to overcome these problems. Mushin, Mapleson, and Lunn'testing them in the laboratory found that their primary failure when applied to infants was the high inspiratory How which could not be adequately reduced. This caused either overinflation, or premature triggering of the cycling mechanism leading to underinfation. The suggested solutions to these problems consisted of either building leaks into the

1 From the departments of Anesthesia and Respiratory Therapy, Children's Hospital Medical Center and the department of Anesthesia, Gundersen Clinic, Ltd., La Crosse, Wisconsin.

${ }^{2}$ Department of Anesthesia, Gundersen Clinic, Ltd., La Crosse, Wisconsin.

aDirector, Anesthesia Department, Children's Hospital Medical Center; Associate Clinical Professor of Anesthesia, Harvard Medical School.

'Directot, Respiratory Therapy Department; Associate in Anesthesia. Children's Hospital Medical Center; Clinical Associate in Anesthesia, Harvard Medical School. 


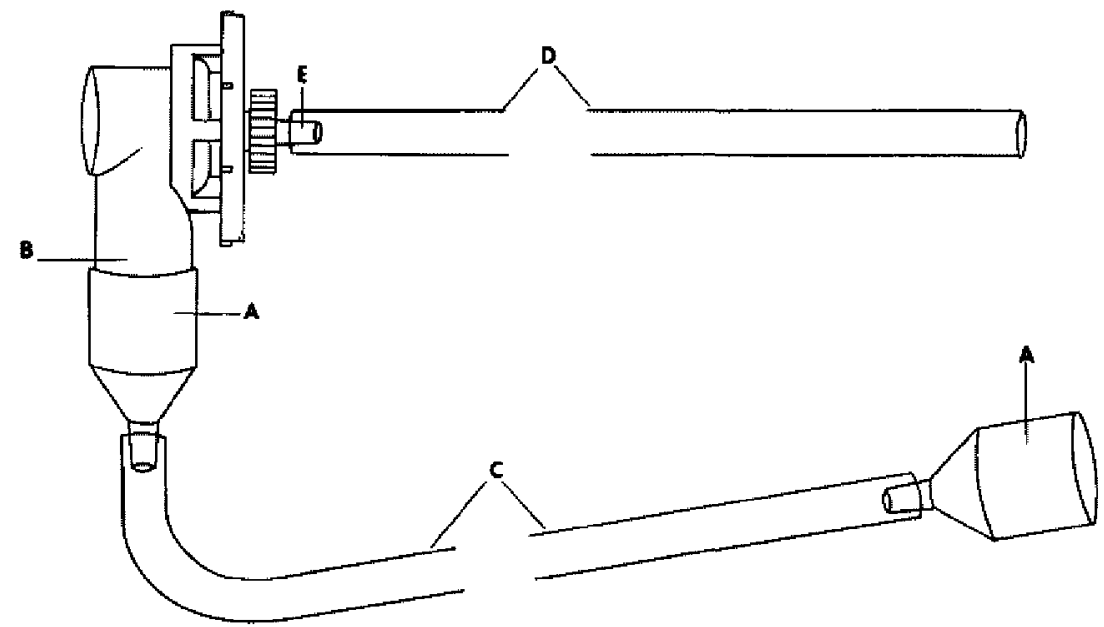

Frgure 1. Schematic diagram of infant modification of Bennett MA-I ventilator. Patient's side: (a) DeVilbiss oxygen connector. (b) Inflow port of minimum deadspace nanifold. (c) Large bore tubing (4.7 $\mathrm{mm}$ ID). (d) Small bore tubing ( $3.5 \mathrm{~mm}$ ID). (e) Valve stem.

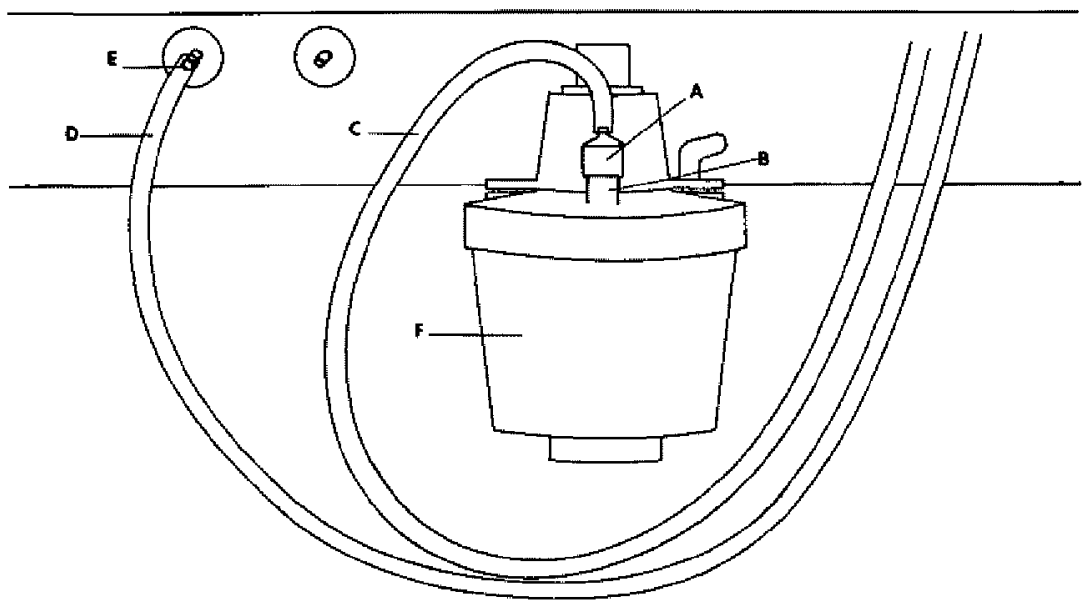

FICure 2. Schematic diagram of infant modification of Bennett MA-I ventilator. Machine side: (a) DeVilbiss oxygen connector. (b) Outflow port of Cascade humidifier. (c) Large bore tubing (4.7 $\mathrm{mm}$ ID). (d) Small bore tubing (3,5mm ID). (e) Bennett MA-I expiration valve. ( $f$ ) Bennett Cascade humidifier. 
circuit utilizing parallel compliance and resistance, introducing a resistance into the inspiratory path, or modifying the ventilator.

Ahlgren et al., ${ }^{5}$ Haddad et al., ${ }^{6}$ Tunstall et al., ${ }^{7}$ have modified ventilators for adults so that they may be used on infants. Okiman ${ }^{8}$ devised a formula and constructed a nomogram for infants when using the Engstrom ventilator. The major disadvantages of these modifications include expensive and time-consuming alterations to the ventilator, inability to adapt all ventilators in this fashion and diffculties in reconverting them back to their original use. In order to overcome some of these disadvantages we suggest that the Bennett MA-I respirator be modified for use in infants by the following:

1. A minimum deadspace manifold $\# 0586$ by Puritan Bennett Corporation

2. A Bennett small tube assembly \#2873

3. Two DeVilbiss oxygen connectors $\# 38335-105$

\section{Adaptation of the Bennett Ma-I Ventilator}

The wide end of a DeVilbiss oxygen connector is slipped over the inflow port of the minimum deadspace manifold and the wide end of the other DeVilbiss oxygen connector is slipped over the outflow port of the Cascade humidifier on the Bennett MA-I ventilator.

The large bore tubing ( $4.7 \mathrm{~mm}$ ID) of the Bennett small tube assembly set is then attached to the small end of the DeVilbiss connector on the manifold and on the Cascade humidifier. The small bore tubing ( $3.5 \mathrm{~mm}$ ID) of the Bennett small tube assembly is attached to the valve stem on the minimum deadspace manifold and the expiration valve on the side of the Bennett MA-I respirator. The unit is now ready for operation. The outllow port of the minimum deadspace manifold can be attached to a $15 \mathrm{~mm}$ endotracheal tube adaptor or to a tracheostomy tube by means of a $15 \mathrm{~mm}$ tracheostomy tube adaptor (see Figures 1 and 2 ).

The Cascade humidifier is filled with sterile distilled water and the thermostat is set between 3 and 4 . The unit is tumed on to heat the water, the volume control is set at zero, the peak flow rate is set at 50 L.PM, and the pressure limit is set at $60 \mathrm{~cm} \mathrm{H}_{2} \mathrm{O}$. If it is necessary to decrease the tidal volume further, the pressure limit may be decreased, thus reducing the delivered tidal volume.

An inspired oxygen concentration is selected based on arterial blood gases, colour, blood pressure, temperature, chest expansion, and breath sounds. The automatic sigh on the ventilator is not used due to the danger of inadvertent overinflation. The infant's lungs may be manually "sighed" using a modifed Ayre's T-piece and bag.

The nebulizer of the Bennett MA-I is eliminated when the infant modification is used. The "PEEP" attachment is compatible with this system and its use is described in the Bennett MA-I Instruction Manual. ${ }^{9}$

Following attachment of the infant to the ventilator, arterial blood gas determinations are made and vital signs monitored. The patient's colour and chest expansion are noted, and sternal or intercostal retraction is watched for. The lungs are auscultated to determine that all areas are being ventilated.

Based on these observations, necessary changes are made on the ventilator. 

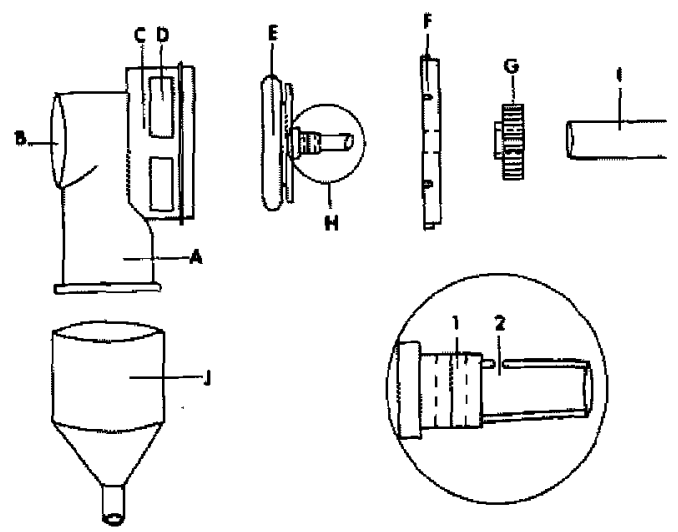

Ficure 3. Schematic diagram of component parts of minimum deadspace manifold: (a) Inflow port. (b) Outflow port. (c) Housing for mushroom valve. (d) Exhalation port (e) Mushroom valve. ( $f$ ) Housing cap. ( $g$ ) Knob holding valve stem against housing cap. ( $h$ ) Enlarged view of valve stem /1. threads /2. 073 inch hole. (i) Small bore tubing ( $3.5 \mathrm{~mm}$ ID). (j) DeVilbiss axygen cannector.

One may have to increase the tidal volume to accommodate to larger infants and to compensate for any leaks around the nasotracheal tube or for mechanical deadspace. Due to the small diameter of the inspiratory tubing connecting the Cascade Humidifier to the minimum dead-space manifold, it may become occluded with condensed water. If this occurs, the line is emptied and the humidifier thermostat reset.

If assisted ventilation is desired, the sensitivity of the device is increased and the rate is decreased. In patients requiring assisted ventilation, as opposed to controlled ventilation, the mushroom valve should be removed from the minimum dead-space manifold and a .073 inch hole is drilled with a $\# 49$ drill bit through one side of the valve stem next to the beginning of the threads on the stem (see Figure 3). The purpose of this hole is to vent off the excess pressure which is used to close the valve to the atmosphere during inspiration.

\section{Discussion}

To ventilate both adult and infant lungs, one must purchase either a separate ventilator for adults and one for infants or modify an existing ventilator originally designed for use in adults. This is a burden both from a financial point of view and also from the standpoint of personnel time.

With the modifications described in this paper we have satisfactorily ventilated the lungs of both adults and infants with the same ventilator. This system is easy, simple, inexpensive, and involves little time for the changeover from adult to infant use without extensive alterations. Also, since it is compact and lightweight, it eliminates bulky apparatus and decreases the chance of accidental extubation. Better observation of the patient is also possible. 
When modified for use in infants, one is able to utilize all the Bennett MA-I ventilator systems with the exception of the nebulizer and spirometer. A Wright respirometer may be placed in line at the minimum deadspace manifold and the patient's expired volumes thus can be accurately measured.

To date 122 infants have been satisfactorily managed at the Children's Hospital Medical Center in Boston and at the Gundersen Clinic-LaCrosse Lutheran Hospital. This group of patients included infants with primary congenital heart disease, respiratory distress syndrome, pneumonia, bronchiolitis, hyponatraemia, meningococcal meningitis, and septicaemia. In our series there have been no complications which could be ascribed to the use of the modified ventilator.

\section{SUMMARY}

A simple modification of a ventilator from use in adults to use in infants is described using only a few inexpensive and readily available components; the system is easily set up, involving little time for the changeover. Since the components are compact and lightweight, there is improved observation of the patient and the chance of accidental extubation is decreased. To date 122 infants have been satisfactorily managed without any complications attributed to the modified ventilator.

\section{RÉSUMÉ}

Nous décrivons une simple modification pour transformer un ventilateur d'adulte en un ventilateur d'enfant de façon peu coûteuse et avec des pièces déjà à votre disposition. On peut installer le système facilement en peu de temps et faire le changement de l'adulte à Y'enfant.

Puisque les pièces sont compactes et légères, l'observation du malade est meilleure et moindres sont les risques d'extubation accidentelle.

A date, nous avons ventilé 122 enfants de façon satisfaisante sans complications attribuables au ventilateur modifé.

\section{REFERENCES}

1. Bendixen, H.H. et al. Respiratory care. St. Louis: C.V. Mosby Company (1956), pp. 153-154.

2. SaFar, P. Kunkel, H.G. Respiratory therapy. Philadelphia: F.A. Davis Company (1956), pp. $105-108$

3. Roebins, L.S. et al. Tidal volume losses of volume-limited ventilators. Anesth. \& Analg 46: 428-431 (1967).

4. Musain, W.W. et al. Problems of automatic ventilation in infants and children. Brit. J. Anaesth. 34: 514-522 (1962).

5. Ahichen, E.W. \& Stepres, C.R. Mechanical ventilation of the infant. Anesthesiology. 27: $692-694$ (1966).

6. HAmDaD, C. \& Richards, C.C. Mechanical ventilation of infants: significance and elimination of ventilator compression volume. Anesthesiology 29: 365-370 (1968).

7. Tunstall, M.E. et al. Ventilating the lungs of newborn infants for prolonged periods. Arch. Dis. Child. 43: 486-487 (1968).

8. OxIMAN, L.G. Artificial ventilation by respirator for newborn infants during anesthesia. $I$. A method using a new formula and a new nomogram. Acta Anaesth. Scand. 7: 31-57 (1963).

9. Operating Instruction Manual. Bennett Respiration Products, Inc. Forn 5030P, 1971. 